\title{
An Approach for Solving Multi-Objective Linear Fractional Programming Problem and It's Comparison with Other Techniques
}

\author{
Huma Akhtar ${ }^{1 *}$, Geeta Modi ${ }^{2}$ \\ ${ }^{*}$ Research Scholar Govt. M.V.M. Bhopal, India, \\ ${ }^{2}$ Professor and Head, Department of Mathematics, Govt. M.V.M. Bhopal, India,
}

*Corresponding Author: Huma Akhtar, Research Scholar Govt. M.V.M. Bhopal, India,

\begin{abstract}
This paper presents Harmonic Average and Advanced Harmonic Average technique to solve multiobjective linear fractional programming problem (MOLFPP) to single objective linear fractional programming problem (SOLFPP) and suggested an algorithm for its solution. The proposed method can be illustrated with the help of numerical example. The numerical result in this paper indicates that Advanced Harmonic Average technique is better than other techniques (such as Chandra Sen., Mean, Median, Geometric Mean, New Geometric Average and Harmonic average).
\end{abstract}

Keywords: Linear Fractional Programming Problem (LFPP), Harmonic Average and Advanced Harmonic Average Techniques.

\section{INTRODUCTION}

Linear Fractional Programming deals with that class of mathematical programming problems in which the relations among the variables are linear; the constraint relations must be in linear form and the objective function to be optimized must be a ratio of two linear functions such as profit/cost, actual cost/ standard cost, output/employee, etc and it is applied to different disciplines such as production planning, financial and corporative planning, health care and hospital planning. A study of multi-objective linear programming problem (MOLPP) is introduced in [2] which suggest an approach to set up multi-objective function under the limitation so that the optimum value of individual problem was greater than zero. Sulaiman and Sadiq studied the Multi-objective function by using mean and median technique [4]. Also Sulaiman and Salih studied the multi-objective fractional programming problem by using mean and median technique [5]. Nahar Samsun et al. suggested a new geometric average technique to optimize the objective function where a single objective function is developed from multi-objective functions [1]. In 2016 Sulaiman et al suggested a new technique by using Harmonic mean of the values of objective functions for solving Multi-objective linear programming problem [3].

In order to extend this work, we have defined MOLFPP and suggest an algorithm to solve linear factional programming problem for multi-objective functions by using Harmonic Average and Advanced Harmonic Average techniques. The result is compared with different techniques such as Chandra Sen., Mean \& Median, Arithmetic Average Geometric Average and New Geometric Average. The Advanced Harmonic Average technique gives better result than all those techniques.

\section{MATHEMATICAL FORM OF LFPP}

The mathematical form of LFP problem is given as follows:

Subject to:

$$
\text { Max. } Z=\frac{\left(\boldsymbol{c}^{T} \boldsymbol{X}+\alpha\right)}{\left(\boldsymbol{d}^{T} \boldsymbol{X}+\beta\right)}
$$

$$
\begin{gathered}
A \mathrm{X}\left(\begin{array}{l}
\leq \\
\geq \\
=
\end{array}\right) \mathrm{b} \\
\mathrm{X} \geq 0
\end{gathered}
$$


An Approach for Solving Multi-Objective Linear Fractional Programming Problem and It's Comparison with Other Techniques

Where $\mathrm{X}, \mathrm{c}$ and $\mathrm{d}$ are $\mathrm{n} \times 1$ vectors, $\mathrm{b}$ is an $\mathrm{m} \times 1$ vector, $c^{T}, d^{T}$ denote transpose of vectors, $\mathrm{A}$ is an $\mathrm{m} \times \mathrm{n}$ matrix and $\alpha, \beta$ are scalars.

\section{Multi-Objective Linear Fractional Programming Problem}

Multi-Objective functions that are the ratio of two linear objective functions are said to be MOLFPP which can be defined as:

$$
\begin{aligned}
& \text { Max. } z_{1}=\frac{c_{1}{ }^{T} \mathrm{X}+\alpha_{1}}{\mathrm{~d}_{1}{ }^{T} \mathrm{X}+\beta_{1}} \\
& \text { Max. } z_{2}=\frac{c_{2}{ }^{T} \mathrm{X}+\alpha_{2}}{\mathrm{~d}_{2}{ }^{T} \mathrm{X}+\beta_{2}} \\
& \text { Max. } z_{r}=\frac{c_{r}{ }^{T} \mathrm{X}+\alpha_{\mathrm{r}}}{{\mathrm{d}_{\mathrm{r}}}^{T} \mathrm{X}+\beta_{\mathrm{r}}} \\
& \text { Min. } z_{r+1}=\frac{c_{r+1}{ }^{T} \mathrm{X}+\alpha_{\mathrm{r}+1}}{\mathrm{~d}_{\mathrm{r}+1}{ }^{T} \mathrm{X}+\beta_{\mathrm{r}+1}} \\
& \text { Min. } z_{S}=\frac{c_{s}{ }^{T} \mathrm{X}+\alpha_{\mathrm{s}}}{\mathrm{d}_{\mathrm{s}}{ }^{T} \mathrm{X}+\beta_{\mathrm{s}}}
\end{aligned}
$$

Subject to:

$$
\begin{gathered}
A \mathrm{X}=\mathrm{b} \\
\mathrm{X} \geq 0
\end{gathered}
$$

Where $\mathrm{b}$ is an $\mathrm{m}$-dimensional vector of constants, $\mathrm{X}$ is an $\mathrm{n}$-dimensional column vector of decision variables, $r$ is number of objective functions to be maximized, $s$ is the number of objective functions to be maximized and minimized and (s-r) is the number of objective functions that is minimized. $A$ is an $\mathrm{m} \times \mathrm{n}$ matrix of constants, all vectors are assumed to be column vectors unless transposed(T). $c_{i}, d_{i}$ (where $i=1,2, \ldots, \mathrm{s}$ ) are $\mathrm{n}$-dimensional vectors of constants, $\alpha_{i}, \beta_{i}$ (where $i=1,2, \ldots, \mathrm{s}$ ) are scalars.

\section{SOLVING MOLFPP BY USING THE FOLLOWING TECHNIQUES}

\subsection{Harmonic Average Technique:-}

Step1: Solve each objective function by using simplex technique.

Step2: Check the feasibility of the solution obtained in step1, if it is feasible then go to step3, otherwise use dual simplex technique to remove infeasibility.

Step3: Assign a name to the optimum value of each objective function Max $z_{i}$ say $\varphi_{i}, i=1,2, \ldots \mathrm{r}$ and Min $z_{i}$ say $\varphi_{i}, i=\mathrm{r}+1, \mathrm{r}+2, \ldots, \mathrm{s}$.

Step4: Calculate Harmonic Average $\operatorname{Hav}_{1}=\operatorname{Hav}\left(\left|\varphi_{i}\right|\right), i=1,2, \ldots \mathrm{r}$ and $\operatorname{Hav}_{2}=\operatorname{Hav}\left(\left|\varphi_{i}\right|\right), i=\mathrm{r}+1$, $\mathrm{r}+2, \ldots, \mathrm{s}$.

Step5: Optimize the combined objective function under the same constraints (3.2) \& (3.3) as follows:

$\operatorname{Max.} \mathrm{Z}=\sum_{i=1}^{r} \frac{\operatorname{Max} z_{i}}{\operatorname{Hav}_{1}}-\sum_{i=r+1}^{S} \frac{\operatorname{Min}_{i}}{\operatorname{Hav}_{2}}$

\subsection{Advanced Harmonic Average $\left(A H_{a v}\right)$ Technique:-}

Step1, Step2, Step3 are the same as given in algorithm (4.1).

Step4: Select $m_{1}=\min \left\{\varphi_{i}\right\}, \forall i=1,2, \ldots, \mathrm{r}$ and $m_{2}=\max \left\{\varphi_{i}\right\}, \forall i=\mathrm{r}+1, \ldots, \mathrm{s}$ then calculate 
An Approach for Solving Multi-Objective Linear Fractional Programming Problem and It's Comparison with Other Techniques

$A H_{a v}=\frac{2\left|m_{1}\right|\left|m_{2}\right|}{\left|m_{1}\right|+\left|m_{2}\right|}$

Step5: Optimize the combined objective function under the same constraints (3.2) \& (3.3) as:

$\operatorname{Max.} \mathrm{Z}=\frac{\left(\sum_{i=1}^{r} \operatorname{Max} z_{i}-\sum_{i=r+1}^{S} \operatorname{Min} z_{i}\right)}{A H_{a v}}$

\section{NUMERICAL EXAMPLE}

\subsection{Example.}

Max. $z_{1}=\frac{3 x_{1}-2 x_{2}}{x_{1}+x_{2}+1}$

Max. $z_{2}=\frac{9 x_{1}+3 x_{2}}{x_{1}+x_{2}+1}$

Max. $z_{3}=\frac{3 x_{1}-5 x_{2}}{2 x_{1}+2 x_{2}+2}$

Min. $z_{4}=\frac{-6 x_{1}+2 x_{2}}{2 x_{1}+2 x_{2}+2}$

Min. $z_{5}=\frac{-3 x_{1}-x_{2}}{x_{1}+x_{2}+1}$

Subject to:

$$
x_{1}+x_{2} \leq 2, \quad 9 x_{1}+x_{2} \leq 9, \quad x_{1}, x_{2} \geq 0
$$

Solution: After finding the value of each of individual objective functions, the results are given below:

Table 1

\begin{tabular}{|c|c|c|c|c|c|}
\hline $\boldsymbol{i}$ & $\boldsymbol{\varphi}_{\boldsymbol{i}}$ & $\boldsymbol{x}_{\boldsymbol{i}}$ & $\boldsymbol{H a v}_{\mathbf{1}}$ & $\boldsymbol{H a v}_{\mathbf{2}}$ & $\boldsymbol{A H}_{\boldsymbol{a v}}$ \\
\hline 1 & $3 / 2$ & $(1,0)$ & $27 / 20$ & & 1 \\
\hline 2 & $9 / 2$ & $(1,0)$ & & & \\
\hline 3 & $3 / 4$ & $(1,0)$ & & & \\
\hline 4 & $-3 / 2$ & $(1,0)$ & & $3 / 2$ & \\
\hline 5 & $-3 / 2$ & $(1,0)$ & & & \\
\hline
\end{tabular}

i) Harmonic Average Technique:-

Max. $\mathrm{Z}=\sum_{i=1}^{r} \frac{\operatorname{Max} z_{i}}{\operatorname{Hav}_{1}}-\sum_{i=r+1}^{S} \frac{\operatorname{Min} z_{i}}{\operatorname{Hav}_{2}}$

Max. $Z=\frac{126 x_{1}-10 x_{2}}{9 x_{1}+9 x_{2}+9}$

Subject to:

$$
x_{1}+x_{2} \leq 2, \quad 9 x_{1}+x_{2} \leq 9, \quad x_{1}, x_{2} \geq 0
$$

Hence the optimal solution is:

$\operatorname{Max} . Z=7, \quad x_{1}=1, x_{2}=0$.

ii) Advanced Harmonic Average $\left(A H_{a v}\right)$ Technique:-

$\operatorname{Max.} Z=\frac{\left(\sum_{i=1}^{r} \operatorname{Max} z_{i}-\sum_{i=r+1}^{S} \operatorname{Min} z_{i}\right)}{A H_{a v}} \quad$ where $A H_{a v}=\frac{2\left|m_{1}\right|\left|m_{2}\right|}{\left|m_{1}\right|+\left|m_{2}\right|}$

Max. $Z=\frac{39 x_{1}-3 x_{2}}{2 x_{1}+2 x_{2}+2}$ 
An Approach for Solving Multi-Objective Linear Fractional Programming Problem and It's Comparison with Other Techniques

Subject to:

$$
x_{1}+x_{2} \leq 2, \quad 9 x_{1}+x_{2} \leq 9, \quad x_{1}, x_{2} \geq 0
$$

Hence the optimal solution is:

Max. $Z=9.75, \quad x_{1}=1, x_{2}=0$.

\section{COMPARISON OF THE NUMERICAL RESUlTS}

Comparison of the numerical results which are obtained from the example 5.1 is shown in the following table2:

\section{Table 2}

\begin{tabular}{|c|c|}
\hline Techniques & Example 6.1 \\
\hline Chandra Sen. Technique & 5 \\
\hline Mean Technique & 5 \\
\hline Median Technique & 6.5 \\
\hline Arithmetic Mean & 5 \\
\hline New Arithmetic Average & 8.665 \\
\hline Geometric Mean & 5.931 \\
\hline New Geometric Average & 9.1895 \\
\hline Harmonic Average & 7 \\
\hline Advanced Harmonic Average & 9.75 \\
\hline
\end{tabular}

In the above table, it is clear that the results obtained in example 5.1 when using advanced harmonic average technique is better than other results.

\section{CONCLUSiON}

In this paper, we have defined Harmonic Average and Advanced Harmonic Average techniques and then compare Advanced Harmonic Average technique with other techniques namely Chandra Sen., Mean \& Median, Arithmetic Mean \& New Arithmetic Average, Geometric Mean \& Advanced Geometric Average and Harmonic Average techniques.

The comparisons of these techniques are based on the value of the objective functions. After solving the numerical example, we found that Max.Z which obtained by our technique(Advanced Harmonic average technique) is better than other techniques(Chandra Sen., mean \& median, arithmetic mean \& new arithmetic average, geometric mean \& new geometric average and harmonic average techniques).

\section{REFERENCES}

[1] Nahar Samsun and Alim Md. Abdul, "A new geometric average technique to solve multi-objective linear fractional programming problem and comparison with new arithmetic average technique", IOSR Journal of Mathematics, Vol. 13, No. 3, PP. 39-52, 2017.

[2] Sen. Chandra, A new approach for multi-objective rural development planning, The Indian Economic Journal, Vol. 30, No. 4, PP. 91-96, 1983.

[3] Sulaiman, N.A. and Mustafa R.B.,"Using harmonic mean to solve multi-objective linear programming problems", American Journal of Operations Research, Vol. 6, No. 1, PP. 25-30, 2016.

[4] Sulaiman N.A. and Sadiq G.W., " Solving the linear multi-objective programming problems; using mean and median values", Al-Rafiden Journal of Computer Sciences and Mathematical, University of Mosul, Vol. 3, No. 1, PP. 69-83, 2006.

[5] Sulaiman, N.A. \& salih A. D., "Using mean and median values to solve linear fractional multi-objective programming problem”, Zanco Journal for Pure and Applied Science, Salahaddin-Erbil University, Vol. 22, No.5, 2010. 


\section{AUTHOR'S BIOGRAPHY}
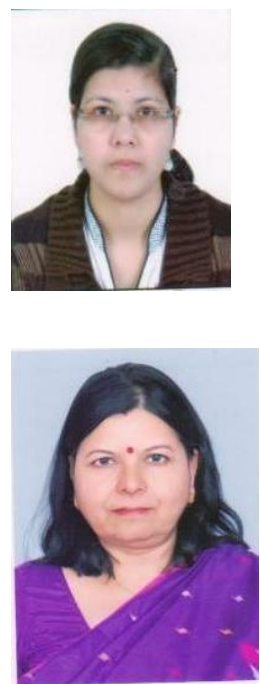

Miss Huma Akhtar is a research scholar in Department of Mathematics, Govt. M.V.M. Bhopal, Madhya Pradesh, India under the Maulana Azad National Fellowship (MANF) for Minority Community. She has 2.8 years teaching experience before awarding MANF for Minority Community. She has been Qualified M.P. SET-2017 and she has published 02 research papers in International Journals and 01 research paper present in the National Seminar. Her area of research is optimization of fractional function and their applications.

Dr. Geeta Modi is working as a Professor \& Head of the Department Mathematics, Govt. M.V.M. Bhopal, Madhya Pradesh, India. She has 34 years of teaching Experience. Presently she is the chairman of central board of studies (Mathematics) Govt. of Madhya Pradesh, India. She is the V.C. nominee member of board of studies IEHE Bhopal Madhya Pradesh India, and she is Ex-Chairman of board of studies (Mathematics) Barkatullah University Bhopal. She has published more than 50 articles in National and International Journals. 13 research scholars awarded Ph. D. under her supervision and 06 research scholars registered now.

Citation: H. Akhtar, G. Modi, " An Approach for Solving Multi-Objective Linear Fractional Programming Problem and It's Comparison with Other Techniques ", International Journal of Scientific and Innovative Mathematical Research, vol. 5, no. 11, p. 1-5, 2017., http://dx.doi.org/10.20431/2347-3142.0511001

Copyright: (C) 2017 Authors. This is an open-access article distributed under the terms of the Creative Commons Attribution License, which permits unrestricted use, distribution, and reproduction in any medium, provided the original author and source are credited. 